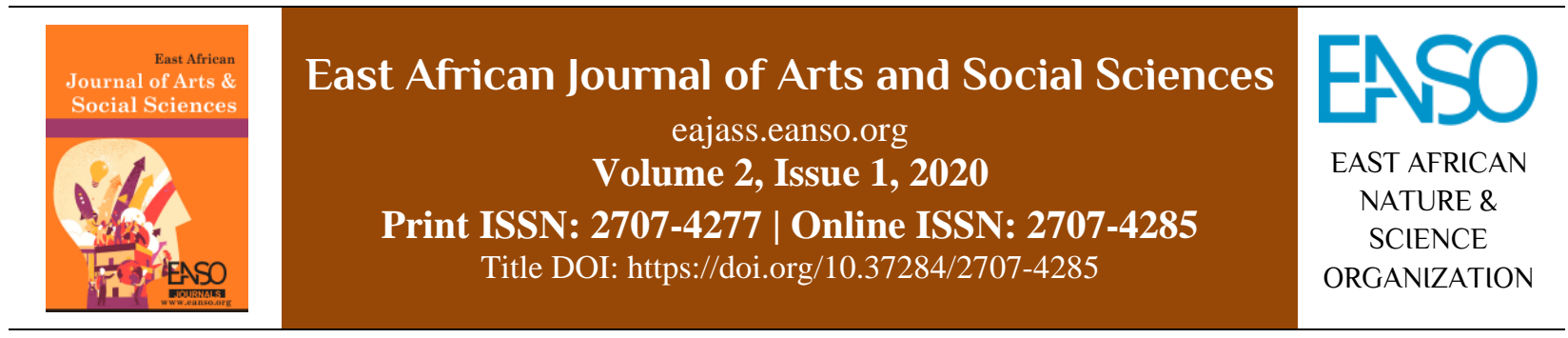

Original Article

\title{
Personal Style in Portraiture Painting - 'Visual Dialogues with Water' Analysis of the Portraiture by Eddy Ochieng
}

\author{
Dr. Kamau Wango, $P h D^{1 *}$ \\ ${ }^{1}$ Kenyatta University, P. O. Box 43844 - 00100, Nairobi, Kenya; ORCID: https://orcid.org/0000-0002-0185-1355. \\ *Author for Correspondence email: kamauwango@gmail.com.
}

Article DOI: https://doi.org/10.37284/eajass.2.1.220

\section{Article history: ABSTRACT}

03 October 2020 Portraiture is arguably one of the most celebrated genres of art and artistic expression through the ages. Artists have always sought to create depictions of

Keywords: themselves in self-portraits as well as the depiction of sitters through in-person posed sessions, referencing, or imagination. They have also used portraiture for

Stylistic Framework, Visual Dialogue, Physiognomy,

Self-Image, Egoism. artistic expression particularly when aiming to depict human feelings and emotions for the practical reason that human expression itself is synonymous with facial expression. It is only through the study of physical facial expression that an artist is able to derive artistic expression in a continuum that ranges from extreme joy signified by laughter to extreme distress, signified by tears. In between the continuum is a whole retinue of feelings and emotions, such as amusement, happiness, irritation, anger, sorrow, despair, fear, anxiety, sadness, and many other human manifestations that emanate from life's experiences. Apart from the obvious outer facial expressions, there are also the innate expressions that underscore personality and character that artists wish to unearth, study, and explore in their subjects. To execute and achieve these expressions in portraiture, the artist uses selected media, styles, and techniques that best suit the desired objective. This paper posits that there exists a correlation between individual style and the effectiveness of the intended purpose of portraiture where effectiveness applies to the communicative or expressive value of a portrait as well as its overall acclaim. It must be noted that there is no portraiture that lacks intent, be it portrayal of likeness from selfportraits or sitters or portraits derived from photographs, thematic referencing that leads to the depiction of certain facial expressions in subject matter or creating portraiture from imagination including surrealistic inspirations. When certain portraiture is at times perceived as not being effective in terms of its 
intent, it is fair to conclude that this may often be as a result of the personal style of the artist or its execution being incompatible with the intended purpose. Hence viewers fail to see or extract what was intended for them to decipher essentially because they are distracted by the personal style. In the same token, when portraiture is seen to be effective, it is often presupposed that this is a result of the personal style of the artist and its execution being deemed compatible with its intended purpose. Hence to a significant extent, the viewer is able to extract this purpose because they are aided by rather than distracted by the style and specifically, personal stylistic rendition. This paper examines the portraiture of Eddy Ochieng, an outstanding Kenyan hyperrealist in order to ascertain whether there exists this visual correlation between his personal style and the intent of his portraiture. He embraces the hyperrealism style featuring some selfportraits as well as of others derived from photographs. The inquiry is whether this style delves into any other meaning other than the quest for the photographic representation of likeness and whether the likeness itself is effectively extracted.

\section{APA CITATION}

Wango, K. (2020). Personal Style in Portraiture Painting - 'Visual Dialogues with Water' Analysis of the Portraiture by Eddy Ochieng. East African Journal of Arts and Social Sciences, 2(1), 134-153. https://doi.org/10.37284/eajass.2.1.220

\section{CHICAGO CITATION}

Wango, Kamau. 2020. "Personal Style in Portraiture Painting - 'Visual Dialogues with Water' Analysis of the Portraiture by Eddy Ochieng”. East African Journal of Arts and Social Sciences 2 (1), 134-153. https://doi.org/10.37284/eajass.2.1.220.

\section{HARVARD CITATION}

Wango, K. (2020) "Personal Style in Portraiture Painting - 'Visual Dialogues with Water' Analysis of the Portraiture by Eddy Ochieng”, East African Journal of Arts and Social Sciences, 2(1), pp. 134-153. doi: 10.37284/eajass.2.1.220.

\section{IEEE CITATION}

W. Wango, “"Matatu' Graffiti as An Avenue for Self-Expression and Social Commentary Among the Youth in Nairobi, Kenya”, EAJASS, vol. 2, no. 1, pp. 134-153, Oct. 2020.

\section{MLA CITATION}

Wango, Kamau. "Personal Style in Portraiture Painting - 'Visual Dialogues with Water' Analysis of the Portraiture by Eddy Ochieng”. East African Journal of Arts and Social Sciences, Vol. 2, no. 1, Oct. 2020, pp. 134-153, doi:10.37284/eajass.2.1.220.

\section{INTRODUCTION}

\section{What Is Portraiture?}

Portraiture is both the process and the skill of creating artistic portraits of people as well as the description of such portraits in their entirety. Portraiture can be done in various media using a variety of styles and techniques. Subsequently, portraiture is rendered in sculpture as busts while in painting, drawing, photography, printmaking and other related disciplines, it is rendered as portraits. Portraiture can be executed within three broad categories. It is usually almost exclusively descriptive of the head, including the face, facial structure, facial expression, the neck up to the shoulders in what is known as a bust. Portraiture may often extend the length of the upper torso in what is called a half-length, and when it features hands in a pose, it is referred to as Kit-cat portraiture. A little less popular is the threequarter-length since it extends up to the knees and hence gives the impression of an incomplete composition. Portraiture can in certain circumstances, also extend to include the entire body in what is referred to as full-length portraiture, depending mainly on the context of the message or 
the intention of the artist; for example, some commemorative portraiture or specially commissioned work usually include a complete body pose as well as the accompanying background. Portraiture may also feature group poses or compositions.

Portraiture is used for various purposes. The very obvious purpose that immediately strikes the mind is the portrayal of likeness, be it a self-portrait or that of any other individual of choice. Before the onset of photography, people, usually aristocrats, would sit to have their portraits painted and the 'sitter' subsequently became a key element in the overall interpretation of portraiture. Other types of portraits were commissioned by the Church and were executed on ceilings and windows. The key motivation of the execution of portraiture, be it selfportraiture or based on a sitter or photograph, is to artistically capture the unique facial characteristics that are descriptive of self or a specific individual's appearance, personality, and character. This type of portraiture has a long history dating from ancient Egypt through the centuries to the contemporary world. There is also the broader artistic purpose that centres on the use of expressive portraiture as a tool for communicating or expressing the desired message, feeling, idea, or opinion and where the portrait is not a self-portrait or necessarily that of a specific individual. For example, an artist in response to a given situation may wish to express a certain feeling like sadness and proceeds to paint a series of portraits entitled faces of despair. Such portraiture would, therefore, not necessarily be selfportraits or other identifiable persons but most likely created faces, purposely constructed and referenced to express the related feeling. Therefore, delving beyond the representational appearance of the subject, it becomes necessary for a portrait to contain a contextual perspective, to harbour identity and to purposefully respond to social issues. Expressive portraiture is therefore used as a broad avenue for the expression of all types of human feelings and emotions that in turn makes them relatable, empathetic and memorable. It must be emphasized, however, that self-portraits can also be used for self-expression beyond the desire for depicting likeness. Self-portraits can transcend their usual role as mere visual representations of individuals to become lenses through which the essence of those individuals is derived.

Portraiture can also be used to propagate the notion of self-reflection, freedom and independence particularly in the context of contemporary art. Some artists now use portraiture as an avenue for the articulation of their identity and cultural heritage as well as focusing their creativity on the conundrum of human experiences that they encounter. The extent to which portraiture is effective as a means of self-expression has attracted a lot of debate and controversy among artists, art historians and critics over time. This has not been so much about the execution of portraits themselves, many of which have been executed to very high standards but about factors influencing their circumstance and development, and the extent to which the viewer is able or even competent to examine interpretive cues in order to 'read' and comprehend the message contained in a portrait.

\section{The Communicative Value of Portraiture}

In describing portraiture, Berger (1994) makes an opening observation that: -

Portraits tell stories, they are interpretations of their sitters, visual narratives for which we assume sitters and painters are, in varying degrees, responsible. In that sense, they are representations of both the sitter's and painter's self-representations (p. 87).

There is no doubt that portraiture is an effective tool for visual communication. It can be argued that one of the most important yet controversial tenets of the communicative strength of portraiture is its physiognomic value. The subject of portraiture, in this case, the sitter, becomes the focus of derivation of glimpses of personality and character, from 
facial and body features and other notable relevant embellishments including attire. This of course presupposes that from an ecphrastic perspective, one can draw an inference of character from a given image - but should it necessarily be so? Berger identifies four strands of commentary that underscore physiognomic narratives which he abbreviates as; character, painter, image and archive. These strands are:

- On the sitter's social, political and or professional status and on his or her character, personality, "Inner being", moral quality and state of mind (mood and emotion, "gli affetti");

- On the painter's characterization and the means by which he produces it;

- On the sitter's pose and appearance as the medium of characterization;

- On the archival data that provides the information used to confirm or fill out interpretations of $a, b$, and $c$ - historical information (or speculations) about lives, behaviour and practices of sitters and painters (Berger, 1994, p. 88).

Berger proceeds to give a critique of this uncritical commitment to the physiognomic interpretation of portraiture based on archival reference and gives insight to what the alternative should be based on; less on the archive and more on the image. He propagates an approach that "consists in redirecting attention from the style and performance of the painter to the style and performance of the sitter as a sitter - that is, not as a character in some historical fiction naturalized by the art historian, but only as a subject of and participant in a particular act of portrayal" (Berger, 1994, p. 94). His argument is complex but gives great insight into the role of the art historian and particularly those of the artist and the sitter in communicating or portraying a profound message to the viewer; which suggests of course that the portrait itself is a crucial tool of visual communication. His theoretical basis is drawn from portraiture of a given period in time where the sitter was the focus of the portrait, but his insightful arguments may be extended to draw interpretive parallels in the examination of the intent and communicative value of portraiture in general even though the sitter is today no longer the central focus and has been replaced by referencing photography.

The intricate matter of what a portrait should portray versus what it actually does or omits, the confines within which the artist conducts his or her work and how the sitter responds to the whole environment including the tricky issue of selfimage, as well as the underlying effects of certain intervening factors, is not a new phenomenon. The content of portraiture has always been put to varying degrees of scrutiny, but the communicative value has always been recognized and appreciated depending on the respective circumstance. In addressing the sitter's self-image, for instance, Schama (2015) puts some perspective to this when he asks "Do subjects want artists to agree with their assumption that the best-looking version of themselves also happens to be the most truthful?" He asserts that "the challenge for any artist trying to capture the lifelikeness of the subject is that a face may freeze into a mask and this may be what is transcribed on to the canvas."

This points to the complexity of interpretation that an artist has to deal with in terms of just when is the sitters face representative of 'itself' or is perceived to be at its most truthful and by extension, therefore, representative of the character and personality therein. On the issue of intervening factors, when a sitter is a private person who draws no controversy, the subsequent portrait portrays the inherent qualities of that individual. But when the individual's history trails him or her, then there is an interference of expectation, similar in context to what Berger (1994) referred to as the archive. Referring to the effect of this adhesion of history upon the artist, Schama (2015) writes: - 
But when the "history" of the sitter is portrayed for the history of the world - or the country he inhabits and must somehow be both exemplary and individual, the challenge becomes daunting. For the painter is now answering not just to the self-image of the sitter, and the creatively disruptive urges of his muse, but to a third party that must be satisfied: public expectation.

In regard to what artists wish to capture in a sitter and often what is interpreted of a portrait, Tjintjelaar (2018) adds a little related insight and visits the issue of the role of the artist and that of the sitter. He asserts: -

Personally, I don't believe that you can capture someone's spirit, or soul or essence, by just merely looking at someone's physical features and deriving someone's internal personal traits by how we perceive their physical traits. The way a person looks, the way a person looks at you and behave, the emotion the person seems to show, they may not be what they really are and are all subject to interpretation, and often wrong interpretation.

Underscoring the complexity and at times, the naivety of interpretation, he further asserts "if a person looks beautiful with a soft look in the eyes, then that says nothing about the person's character." In view of this, one then may ask what the artist in retrospect, seeks to achieve in portraiture. If this traditional quest to portray the character and personality from the image of the sitter, cannot indeed be extracted from their physical features, then what defines the role of the artist? Tjintjelaar gives his apt response:

What we capture is not really the sitter, but oneself and that is what we try to express: one's own desires, one's own grief, one's own imperfections, one's own mortality, one's own privations, and shortcomings. The sitter is the symbol; the meaning is ourselves.
In regard to self-portraits, these have historically been used as an avenue of self-expression and by extension, therefore, as a way of communicating a message to the viewer; there is no self- portraiture in whatever sub-genre that does not say something. Unlike in the case of a sitter, where there often occurs an interpretive tug of war between the intent of the painter and the individuality of sitter, the selfportrait is entirely about the painter as a selfsubject. A descriptive or naturalistic self-portrait, such as photorealism, captures the pertinent features of the individual which, by the strength of their execution, enables the viewer to delve into the individuality of the subject. Some types of selfportraiture are deliberately or blatantly more expressive in terms of their style either by the use of colours, textures, brush strokes, impasto and abstractions; or stepping out of the self, such that one depicts himself or herself as another person. This type of portraiture, as seen through expressionism, becomes more of an emotional selfreflection which then appeals to the empathic viewer; who resonates with, recognizes or subscribes to those emotions. This empathic connection of one individual to another, or even perhaps lack of it, denotes the communicative value of portraiture in this regard. But again, this too has drawn its share of inquiry or even scepticism in terms of the intervening effect of self-image; it is conceivable that the face the self-subject wishes to project in self-portraiture is the one perfectly aligned with their self-image or egoism. That is their perceived strengths and their vanities and less to do with their vulnerabilities.

\section{Approaches to Portraiture Styles}

Artists over time have approached portraiture using different styles mainly informed by their different motivations, inspirations and intentions. Each style bears and follows its own unique stylistic dictates and is guided by factors that gravitate around its formal or descriptive qualities, analytical qualities, symbolic qualities, interpretative or contemplative qualities, interactive appeal, and judgment as well 
as the innate intent of the artist. Portraiture as a genre has always been executed within the realm of the wider artistic styles and therefore like any genre of painting, portraiture reflected the prevailing style of painting, only that these styles were applied at the respective time to suit the intent of the portrait artist or to respond to the influence of that period. Hence approaches to portraiture have transformed, metamorphosed or aligned themselves in general resonance to the dictates of the artistic period, for instance, as seen through traditional portraiture across time to contemporary portraiture. Although this paper focuses on hyper-realism, it is prudent to have a glimpse into other portraiture styles for purposes of a holistic overview. Historically, these styles often overlapped or had a direct influence upon one another. Some of the styles that have often been utilized in portraiture and are still explored today are as briefly outlined here below:

\section{Impressionist Portraiture}

A major tenet of impressionist portraiture was to replicate or imitate nature. Impressionist portraiture just like the mainstream impressionism subject matter was characterized by short, thick strokes of paint that sought to capture the essence of the subject instead of details. Artists used wet to wet method where the paints were applied impasto. Since they did not wait for successive layers of paint to dry, they worked fast to produce fine edges and colour interactions. There are artists who are, today, still inspired by this approach to portraiture.

\section{Expressionist portraiture}

Expressionist portraiture focuses on the communication of meaning as well as the expression of emotional experiences. These emotions are seen from three perspectives; those of the artist, those of the featured subject and those of the viewer making expressionist portraiture a confluence of three emotions. Expressionist portraiture hence de-emphasizes representational likeness of self or featured subject. This type of portraiture is often characterized by formal distortion, application of non-naturalistic or arbitrary colours and unusual backgrounds. One of the most outstanding proponents of expressionist portraiture said of his approach "Instead of trying to reproduce exactly what I have before my eyes, I use colour more arbitrarily, in order to express myself forcibly" (Van Gogh) (Riley, 1995, p. 99).

\section{Abstract portraiture}

Abstract portraiture refers to the creation of portraits that seek to avoid all aspects of a representational approach to reality and instead focus on the realm of ideas that delve, to a great extent, upon subjectivity and life's experiences. Barcio (2016) notes:

To be considered an abstract portrait, an artwork must incorporate two faculties: first, it must utilize the concept of portraiture in some way; and second it must be abstract, meaning it must deal with the realm of ideas, or at least avoid a purely objective or representational approach to reality.

Abstract portraiture hence emphasizes upon a nonrepresentational approach based primarily on the view that the effect of empathy and particularly the depiction of faces that bear recognizable likeness often elicit personal prejudices, anxieties and generalizations in the mind of the viewer that ultimately diminish the intended ideas of the artist. Abstraction in portraiture just like in the mainstream style may be executed within a continuum ranging from slight or partial abstraction to total abstraction. Barcio further notes that: -
Abstract portrait artists confront peculiar challenges. When we see faces in everything; that is called pareidolia. When we see everything in faces; that is called empathy. Abstract portraits inhabit a space somewhere between the two, and their artists must contend simultaneously with both. 
Some of the outstanding proponents of abstract portraiture were Pablo Picasso and Willem de Kooning

\section{Cubist Portraiture}

Cubist portraiture, just like the broader cubism movement, gravitates around three tenets of visual execution; flatness became an important component of visual execution approach among cubist painters where they forfeited shading in order to bring together both the background and the foreground, by de-emphasizing anyone upon the other. Geometric shapes were used to describe forms thereby simplifying the representation of subject matter and thereby reducing the visual load. The use of multiple perspectives enabled the painters to depict subject matter from various simultaneous points of view. Due to this fundamental alteration of style, cubist portraiture subsequently becomes synonymous with abstraction. The term cubism originated from the early criticism of painters who were seen to no longer objectively replicate the world. Subsequent paintings, particularly by Pablo Picasso and George Braque, two figures associated with the founding of cubism, were dismissed as being composed of 'cubes.' The name was ultimately adopted after being initially embraced by Guillaume Apollinaire, a friendlier critic at the time.

\section{Realism}

Just like realism in painting encompassed accurate and natural representation of nature or contemporary life, realism in portraiture embraced detailed naturalistic studies of the subject based on close observation of facial features and appearance. Realist portrait painters avoided unnecessary embellishments or imaginative idealization of the subject other than what would already be part of regalia or immediate relevant background in the case of portraiture that extended downwards or included full figures postures.

\section{Photorealism (Super-realism or Hyperrealism)}

Photorealism, often also referred as super-realism or hyperrealism originated in America in the 1960s and 1970s where artists, relying on a photo as a foundation of their work, sought to recreate the effect of the photo on a surface such canvas through painting or drawing, using a selected medium such as pastels, charcoal or paints. Their technique involved projecting a photo onto canvas or using the underlying grid-structure and subsequently reproducing its effect by use of an airbrush and finishing the picture through painting.

\section{Hyperrealism}

Hyperrealistic portraiture is a sub-genre of portraiture that is often described as surpassing photorealism with the intention of creating a study of a self-portrait or sitting subject to its finest naturalistic/realistic detail, making it often irrespective of the medium, indistinguishable from photographs. The motivation is to meticulously study minute details in order to surpass photographic representation and create a 'counter realm' of representational likeness or what has been termed as 'illusion of a reality' with details that exist, or perhaps do not exist, which are never really captured or seen by the human eye. This is aided by digital imagery. The mere prospect of surpassing photographic representation fascinates both artists and viewers. To a certain extent, artists in this genre, unlike their counterparts in other subgenres, therefore, find themselves confined to certain limitations of scope in terms of choice and application of colours, brushstrokes, aesthetical compositions and expression of certain meanings or feelings including self-expression. However, they are usually not too perturbed by this prospect since they do not wish to necessarily immerse themselves in any of these; in portraiture, their principal objective is to achieve the highest level of likeness and by extension whatever human feeling that emanates from the finesse of their portraiture. However, since they have the manoeuvrability of 
this illusion of a reality phenomenon, they, unlike photorealists, may include some of these expressions of feelings and emotions as emanating from this extended illusion of reality. Meisel (1980) notes:

Furthermore, they may incorporate emotional, social, cultural, and political thematic elements as an extension of the painted visual illusion; a distinct departure from the older and considerably more literal school of photorealism

The work of hyper-realists is still characterized by a tendency towards high illusionism and focus on the subject and less towards details of nature

\section{Surrealism}

Surrealist portraiture has its foundation within the surrealist movement itself that emerged amidst the aftermath of World War1 in the 1920s. It propagated at the time of its emergence, the combination of visual and intellectual imagination that emanate from the conscious mind on one hand, with dreams and other random or inadvertent images that emanate from the unconscious mind, on the other. This combination ostensibly resulted in the creation of a state of super-reality. Surrealist portraiture is characterized by a complete departure from or defiance of the traditional description of portraiture and features formal distortion often to levels of grotesqueness. Some of the proponents of surrealistic portraiture include Salvador Dali, Joan Miro, Frida Kahlo, and Francis Bacon. Andre Breton is recognized as the founder of the surrealism movement in 1924; he wrote about the convergence of dreams and reality into "a kind of absolute reality, a surreality" (Cohen, 2019). Breton believed that the unconscious mind from where dreams emanated was the reservoir of creative activity. Surrealism, subsequently, presupposed that the superior qualities of the irrational, unconscious mind had been unduly suppressed by the intellectual movement that hitherto existed and which propagated reason, rationalism, and individualism.

\section{Pop Art Portraiture}

Pop art as a movement began in Britain in the mid1950s and soon spread to the United States. It was propagated by activists, artists and other likeminded thinkers who sought to deviate from the regular social conformity. Closely linked to the consumer culture of the time, some major characteristics of pop art emerged to be recognizable imagery, bright colours, humour, innovative mass production techniques such as printmaking, screen printing and lithography, as well as the use of mixed media and collage. Portraiture is executed by reducing details of a photograph to basic tones of light and dark and then enhancing the resultant image with bold, bright colours, tones, patterns and textures and retaining the likeness of the subject or creating an imaginary one. A major proponent of pop art was Andy Warhol.

\section{Description of Personal Style}

An artistic style refers to the manner in which a work of art is executed or subject matter rendered. Specifically, it is how the artist is able to express his/her ideas, feelings, emotions or whatever vision or intent they have in mind using the medium and material of choice. As observed before, a style is determined by its own unique stylistic tenets within which an artist is able to apply formal organization, descriptive, analytical and interpretive characteristics among others. A style is also greatly dictated by the way an artist handles the medium, tools as well as the application of method or technique. In any definition of style, there must also be an element of conviction or philosophical basis for its choice and usage.

Within this stylistic framework, the artist is able to construct and develop his or her own personal style. Many artists are often able to make reference to any original movement of their liking be it 
impressionism, expressionism, cubism, surrealism and many others although they are not described as belonging to those movements; they are only inspired or influenced by the respective movement that they subscribe to. A personal style is developed over time and is susceptible to change as the artist grows, builds confidence and acquires additional knowledge and skills. Although there is no harm in having a multi-style approach in the formative stages of experimentation, an artist is advised to consolidate a style that best helps to achieve his or her artistic goals particularly as it applies to selfexpression

\section{Portraiture as an Avenue for Self-expression}

Artists in art and photography have used portraiture for self-expression across the passage of time, whether in reference to self-portraits or studying other subjects as sitters. McDonald (2018) referred to the work of Jennifer Kiaba who aptly described self-portraiture from her perspective as "Selfportraiture, for me, is a tool for self-exploration. I use it to peer into my psyche, and to begin to unravel the inner workings there."

Although referring to portraiture in photography, French photographer, Juliette Jourdain adds another perspective to the use of self-portraiture as a means of self-expression, she writes: -

The goal of my self-portraits is not to express myself, but more to get people's imaginations going and get them to rely on them with their own stories and feelings," she explains. "My self-portraits also stimulate my own imagination with freedom, but also everyone else's. I love making them and re-invent myself every time. I love to make people feel all sorts of emotions. And make them wonder (McDonald, 2018).

American fine art photographer Brooke Shaden adds an aspect of a fantasy aspect to the use of selfportraiture when he posits: -
Self-portraiture is my way of creating the characters I wish I was. I often daydream of faraway lands and the people who inhabit them, and I love to pretend that I am one of those people from one of those lands (McDonald, 2018).

As observed, the use of self-portraiture as a tool for self-expression has undoubtedly been in existence across time, but it has, however, not failed to attract a fair measure of scrutiny as to the extent of its effectiveness as well as what should be its motive in view of a number of intervening factors. Some of these factors have been identified as the essence of the self, the environment, influence of society and the projection of self-image as presented to others. Although it is not within the scope of this paper to delve into the intricacies of these inquiries, the matter of the effectiveness of self-portraiture as an avenue for self-expression is raised in three theories that are, however, worth noting. Crozier and Greenhalg (1988) identified three psychological theories to determine whether such theories could provide insight into viewers' responses to selfportraits. They subsequently focused on selfawareness theory, self-presentation theory and social constructionist theory.

In the case of self-awareness theory, in reference to the input of Carver and Scheier, a major observation that stood out in regard to selfexpression which could be seen as formatively relevant in the context of this paper is the "distinction between the private self and the public self as objects of awareness: when one is conscious of one's private self, one is attentive to one's inner thoughts and feelings; when one is conscious of one's public, one is aware of oneself as a social object" (Crozier \& Greenhalgh, 1988). In the case of self-presentation theory, the core matter of argument is the essence of self-presentation and by extension the motives for producing self-portraits or whether indeed self-portraits can be construed to be self-presentations. Self-presentation is here defined in terms of "those aspects of a person's 
behaviour that are designed to influence the impressions that other people will form of that person" (Crozier \& Greenhalgh, 1988). An interesting motive highlighted in this theory that may bear some insight into why artists undertake self-portraiture is summed up thus:

The motives that might best characterize current practice do seem to reflect selfpresentational concerns, but the self to be presented is not just one role or mask nor is the goal not just to enhance one's reputation in the eyes of others but to tell the truth about oneself both to oneself and to others (Crozier \& Greenhalgh, 1988, p. 30).

Social constructionist theory weaves the concept of the self as being modelled by or intertwined with social dynamics as they unfold over the course of time, which in turn manifest themselves in selfportraiture. Crozier and Greenhalg (1988) refer to the work of Hallowell who argues that "the individual's self-image and his interpretation of his own experience cannot be divorced from the concept of self that is characteristic of his society". They posit that the outcome or implication of all this is that the self-portrait will have different meanings for people at different times. They further state that: -

The psychological meaning of a self-portrait is a complex one. It needs to be explained in terms of theories which do justice to the social dimension. One might even say that the selfportrait literally can lose its meaning if the significance of such factors as patronage, style, the status of the profession, religion or wider social and economic trends are ignored (Crozier \& Greenhalgh, 1988, p. 30).

The purpose of highlighting these arguments is not to make any conclusion on the respective manifestation of the theories but rather to demonstrate the various perspectives that are often at play when an artist seeks to create a self-portrait that depicts his or her self-expression and even more so when that portrait is presented to viewers. However, perhaps a confluence of these theories, with some aspects of each complementing one another should, as described, give a clearer picture of the motive, role and place of self-portraiture as well as why it is significant in self-expression.

\section{Historical Foundations of Portraiture - Traditional/Contemporary}

When exploring portraiture, it is always fitting to be aware of the historical foundation of this important genre and how it transformed over time as well as factors that contributed to this transformation. This is particularly in reference to motive, social dynamics, rendition, new discoveries and individual inspiration that influenced the nature and description of portraiture in the respective phases of time. The history of portraiture itself goes back to ancient Mediterranean civilizations and weaves its way to Roman portraiture, portraiture of the late antiquity and the middle ages, Byzantine style of portraiture, the influence of Italian renaissance, the post-renaissance period including the famous Baroque portraiture, the Dutch realism influence, the great expansion of portraiture during the $18^{\text {th }}$ and $19^{\text {th }}$ Centuries into the $20^{\text {th }}$ Century where there occurred a significant deviation from the old classical hierarchy of genres. Portraiture took a new direction in the advent of major word occurrences at the turn of the $20^{\text {th }}$ Century. Artists were no longer interested in the classical hierarchy of genres and the effect of the onset of photography on art and other factors such as wars and technological advancements left artists no option but to seek to redefine artistic styles in the $20^{\text {th }}$ Century. This subsequently led to the establishment of many of the modern art styles, including new explorations in portraiture. Hertzmann (2018) observes:

It seems likely, in fact, that photography was one of the major catalysts of the Modern Art movement: its influence led to decades of vitality in the world of painting, as artists were 
East African Journal of Arts and Social Sciences, Volume 2, Issue 1, 2020

Article DOI: https://doi.org/10.37284/eajass.2.1.220

both inspired by photographic images and pushed beyond realism. Without photography, perhaps modern art would never have existed.

\section{ANALYTICAL FRAMEWORK}

In order to analyse the work in this paper, this study applied a formal analysis that is used to analyse any work of art. Formal analysis is a technique applied in the organization of visual information and helps a viewer to decipher and perhaps even comprehend the visual impact envisioned or intended by the artist. However, the formal description of artwork is often accompanied by other strategies that culminate in a holistic analysis of work. Hence beyond description or what can immediately be seen in any artwork in terms of use of elements, as well as observation of principals of composition, this paper identified interpretation as being fundamental in the overall analysis of portraiture. Subsequently, based on these elements and principles, the viewer delves into the intent, feeling, mood or even meaning attached to the portraiture. Apart from the concept of likeness which is a fundamental intent of portraiture, the viewer delves further into the individuality or personality of the subject, whether indeed there is an unravelling story and what emotions are visually or suggestively inherent. This, in turn, culminates in another vital strategy which is judgment which accords the viewer an opportunity to form an opinion based on his/her analysis and interpretation.

Barrett (1994) categorizes formal analysis in four levels, namely; description, analysis, interpretation and judgment. Description refers to the fundamental visible nature of the artwork including its form, technique and style and addresses itself to what the viewer sees. Analysis refers mainly to the execution of the work including the usage of elements and principles of art, composition, as well as generation of subject matter; it addresses itself to how the work was done. Interpretation delves into the meaning of the artwork or its broader thematic context and it addresses itself to why the artist created the work as it appears including the possible motivation or inspiration. Judgment refers to the overall quality of work as well as its originality. This often gives rank to one piece of art against another. Judgment hence establishes certain criteria for evaluating a work of art and identifies evidence that meets each criterion in order to culminate in value judgment. In lending credence to the identification and use of interpretation as an appropriate interpretive tool, Barrett (1994, p. 8-13) further states that;

1). Interpretations are persuasive arguments. 2). Interpretations are not so much absolutely right, but more or less reasonable, convincing, enlightening, and informative. 3). All art is in part about the world in which it emerged. 4. No single interpretation is exhaustive of the meaning of an artwork. 4). The meanings of an artwork may be different from its significance to the viewer. Interpretation is ultimately a communal endeavour, and the community is ultimately self- corrective. 5). Good interpretations invite us to see for ourselves and to continue on our own. 


\section{Analysis of Work}

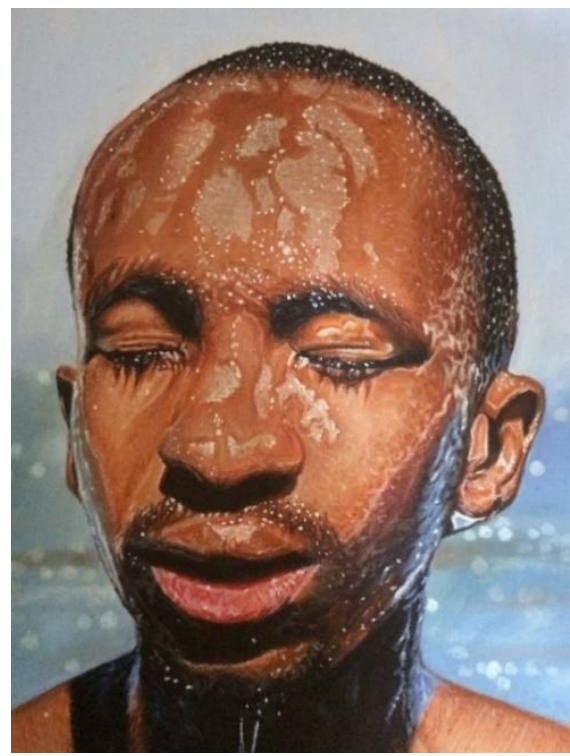

\section{Plate 1: Crystal clear series}

$45 \mathrm{~cm} \times 55 \mathrm{~cm}$

Medium: Oil on canvas

2017

The young man (Plate 1) seems to have freshly emerged from the water by the beach and the remnants of water drip down his face. His forehead depicts a diminishing film of water starting to part away from his skin showing the effect of rapid drying amidst the heat of the day. The heat of the day is itself depicted by the shine on his face showing that it's a sunny and pleasant day. The effect of dripping water on his face and the wetness of its flow is remarkably well-executed. The artist uses shadows below the nose and lips and around the neck to create the necessary contrasts to show the effect of the sunshine falling upon the face. The face itself is well executed with intricate all-round details with smooth African skin texture. It is notable that the artist skilfully combines the textural effect of hair with the wetness of the water to create a sparkling effect that is pleasant to view. In terms of expression, the face depicts a moment of 'serene ecstasy' characterized by closed eyes and lips slightly ajar, as the individual absorbs the effect felt by his liaison with the ocean water. The portrait

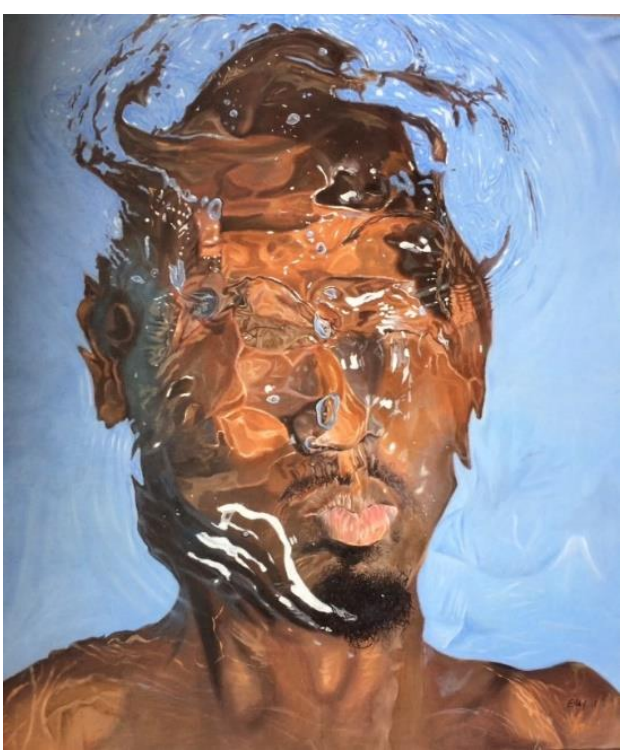

Plate 2: Crystal clear series

$85 \mathrm{~cm} \times 100 \mathrm{~cm}$

Medium: Oil on canvas

2017

permeates a feeling of contentment from within and cannot be seen as merely a study of the effect of water on the skin, but what water does to your inner being, to calm your soul even if it is just momentarily.

In the self-portrait (Plate 2) the face and shoulders are entirely emersed in crystal clear water, the action of which creates intriguing wobbling waves of water that completely distort the facial structure. The crystal-clear water then becomes a lens through which the face is seen and what emerges is an arbitrary abstraction of the face, which, however, creates a new dimension of expression. The artist, therefore, succeeds in creating an effect that makes the viewer make this description since it aptly mimics the waves in the real physical situation. Unlike in the other portraits where the artist is confined to or obliged to show hyperrealistic details, the effect of submerging of the face sets him free of those details, which in essence is what abstraction actually does; it breaks down realistic 
details to arbitrary geometrical anecdotes. The brushstrokes are relaxed and carefree and tones well overlapped. This effect accords the artist the freedom to explore the portrait afresh and assign it new meaning. In examining the portrait, the sense of serenity, for instance, observed on the face (Plate 1), disappears and is replaced by a sense of distress and anxiety not only implied by the distortion of the

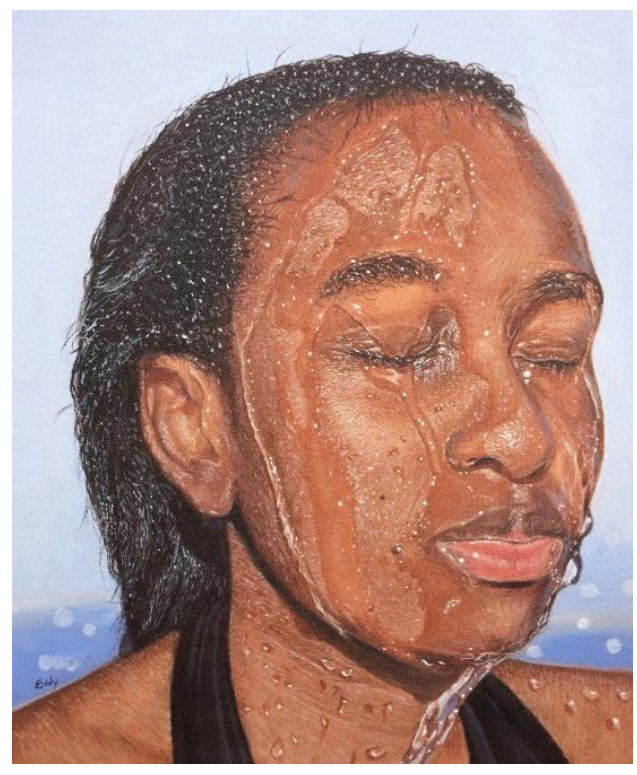

\section{Plate 3: Crystal clear series}

$45 \mathrm{~cm} \times 55 \mathrm{~cm}$

Medium: Oil on canvas

2017

The young woman in (Plate 3) has just emerged from a dip in the ocean waters and the residue water subsequently drips down her face. The artist studies this drip in very good detail and the depiction of the transparency of the water is remarkable. The rest of the facial details are executed with equal precision bringing out the uniqueness of each facial feature and holistically emphasizing the beauty of this truly African woman. The lips perhaps suggest a slight exhale of breath which is associated with contact of water upon the body. The tone of the smooth African skin, the texture of the wet hair and the use of shadows to show the effect of light are all brought out convincingly. The artist as is characteristic of his style expresses feeling through face created by the waves but also by the tightened lip. The subject is no longer defined; one can no longer make out his individuality; he is swallowed and constrained in another world. This is an interesting phenomenon because while the artist started by the meticulous study of the effect of a submerged face in crystal clear water, he ends up with an abstracted face that harbours new meaning.

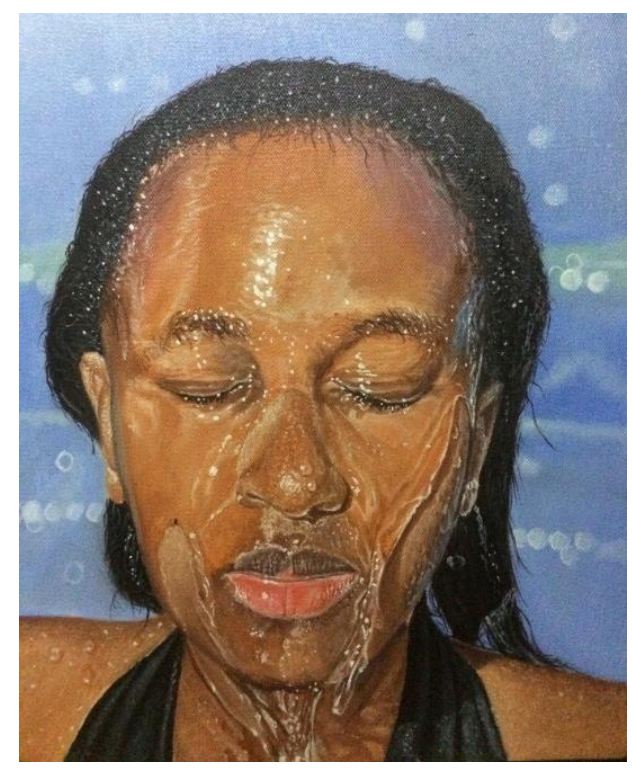

Plate 4: Crystal clear series

$45 \mathrm{~cm} \times 55 \mathrm{~cm}$

Medium: Oil on canvas

2017

the closed eyes. Through closed eyes, the woman retreats into a moment of serene meditation and the artist makes one feel that the closed eyes are not merely because of the physical effect of dripping water, but because of the inner feeling of personal tranquillity, it emanates which then perhaps underscores the dialogue with the water. That is where the significance of the portrait perhaps lies; that it is possible to extract feeling through the closed eyes. One gets the feeling that the eyes are not closed merely because of the physical contact with water, but because of the exhilarating effect of 'dallying' with water. 
The sequel painting (Plate 4) is another angle of the same individual featured in Plate 3. The painted characteristics and approach are similar but the spontaneity of poses in both portraits when viewed together, side by side, aptly emphasizes the notion of an inner feeling created by the effect of dripping water upon the face and, by extension, the interaction with ocean water. There is more than meets the eye beyond the physical water running down the face; it certainly takes the woman to another place, so the paintings suggest. The two portraits also show the artist's skill in bringing out the exact likeness between the two faces even though they are executed from different angles. This is significant because it is usually a difficult task for any artist to duplicate and balance key features of likeness in two different paintings to make the faces look completely identical. In this

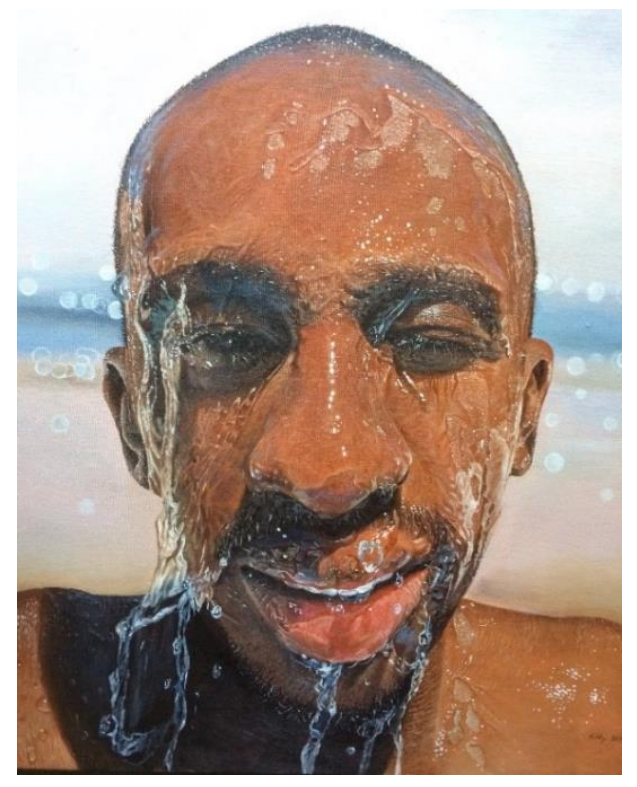

Plate 5: Crystal clear series

$85 \mathrm{~cm} \times 100 \mathrm{~cm}$

Medium: Oil on canvas

2017

The artist continues with his thematic exploration of the effect of water on the human body and in this self-portrait (Plate 5) he paints a gush of water running down his face which is the effect that occurs immediately after one emerges from a dip case, the artist also succeeds in depicting the effect of flowing water such that it looks like it is the same scoop of water flowing in each of the portraits only that it is viewed from a different angle. This duplicative precision is of course a characteristic of photography, which is a key ingredient in the process of creating hyperrealism. Photography does not need to grapple with such artistic intricacies; it simply mechanically duplicates all features as many times as necessary and in as many angles are required, but the artist, however, is able to carry out the cues with meticulous precision. When facial images close their eyes, they are no longer dialoguing with the viewer; they are dialoguing with themselves. When one looks at the simultaneous faces in both Plates 3 and 4, they portray no interest in the viewer; they are entirely engrossed in their inner feelings.

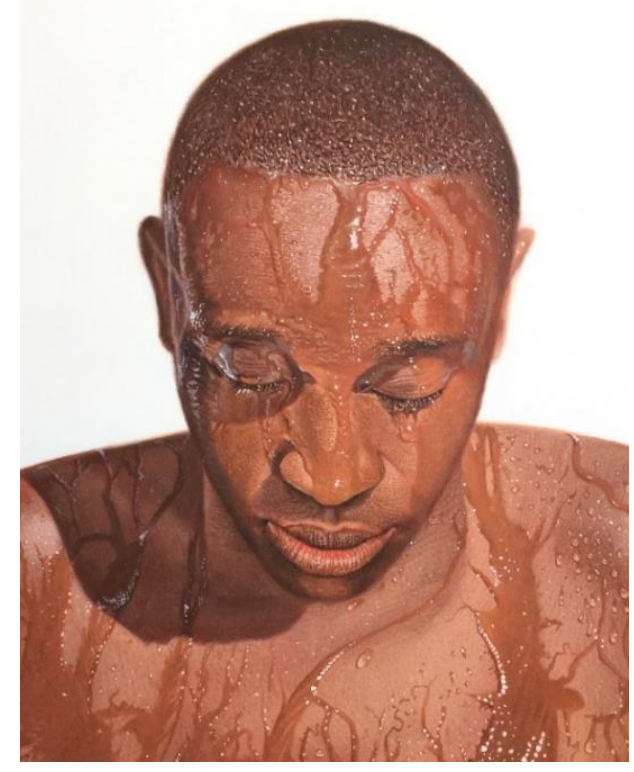

Plate 6: Crystal clear series

$95 \mathrm{~cm} \times 140 \mathrm{~cm}$

Medium: Oil on canvas

2017

into a body of water. He paints the water in his characteristic manner showing the transparency and purity of the water as well as the wetness it creates on the face. In this portrait, he depicts the uninterrupted movement and speed of the flow as 
the water transcends the face. The speed is depicted by the water running from the eyebrow, flowing over the eye and 'splashing' off the side of the face to the collar bone and other parts of it literally flowing over the lips. He conveniently uses shadows to create the necessary contrasts that help to bring out the feeling of the water as shown on the left side of the portrait. What perhaps remains profound is the artist's ability to spontaneously depict the wetness on all parts of the face yet retain the quality of the skin tone to imply a smooth, rich African skin as well as the accuracy of other facial features. This then means that the effect of flowing water on the face, while powerfully executed, does not interfere, distort or impede the quality of details that make up the face itself such that the face remains clearly identifiable and pleasant to view as its own study. This skill of having two aspects of his technique applied to complement each other rather than cause visual conflict is what makes the holistic portrait a worthwhile painting and enables

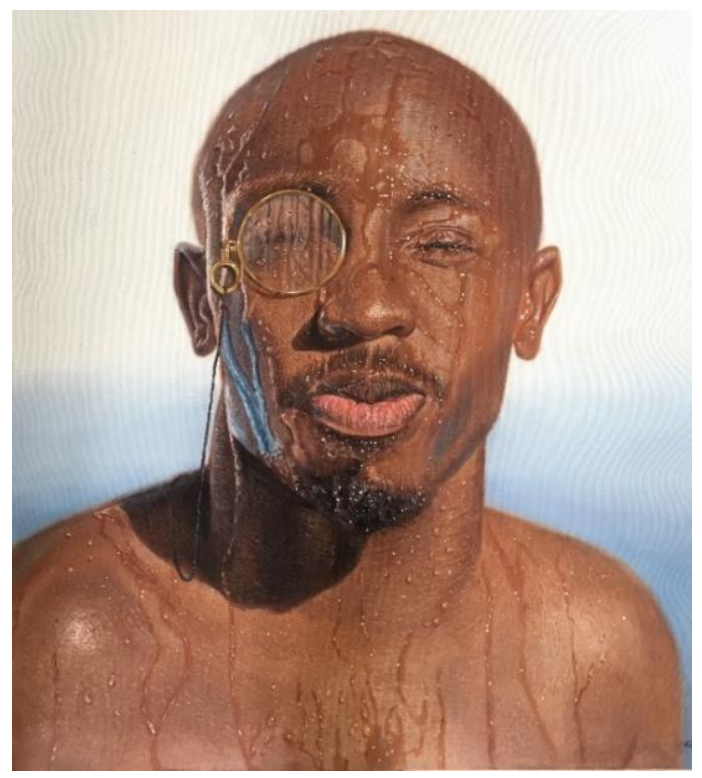

Plate 7: Self-portrait

$65 \mathrm{~cm} \times 90 \mathrm{~cm}$

Medium: Oil on canvas

2017 the viewer to make out the face as a self-portrait. In this portrait, the artist portrays a pleasant half-smile characterized by a slightly open mouth and open eyes slightly blurred by flowing water. This portrayal creates the feeling of 'therapeutic joy' and the expression of contentment in the individual's interaction with water.

The water has ceased to flow, but its wetness still lingers on the skin surface as it begins to dry up in the hot sun (Plate 6). The face is executed with precise details with shadows and textural effects applied to enhance the overall portrait, as shown in the short-wet hair and light effects on face and body. The individual looks down as if to savour the moment of his encounter with the water in a 'moment of meditation'. This portrayal of a moment of meditation denotes the feeling created by the portrait beyond just the physical emergence from the water.

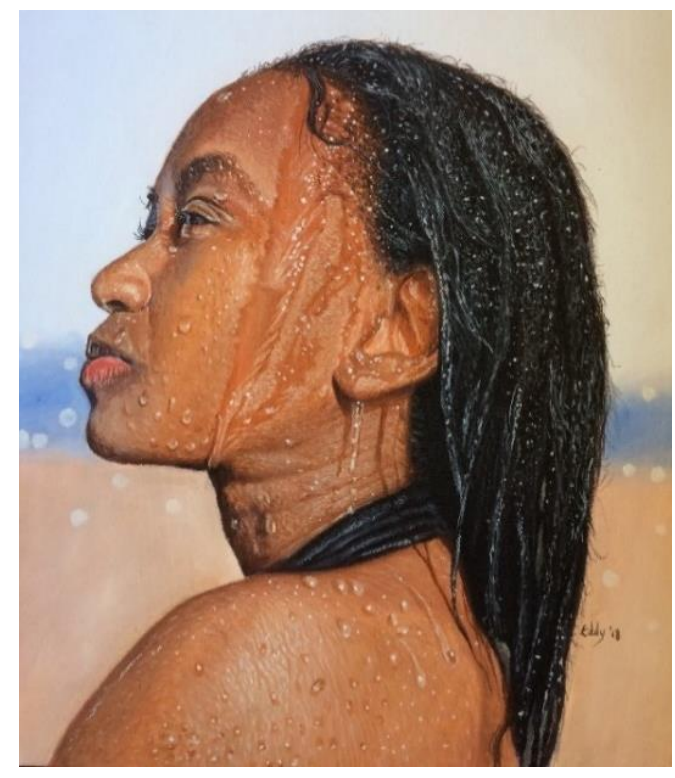

Plate 8: Crystal clear series $45 \mathrm{~cm} \times 55 \mathrm{~cm}$

Medium: Oil on canvas

2017 
In the self-portrait entitled 'point of view,' the artist (Plate 7) relishes the interaction with water. As remnants of water trickle down his face and body, the expression on his face depicted by his closed eyes and slightly tightened lips, creates the feeling of momentary contentment and joy. The artist studies his own face with convincing detail and depicts the tonal variation on the body skin almost as if to show the effect of the sun upon the skin. Shadows are used effectively on the left side of the portrait to create clear contrasts that suggest the direction and intensity of the sunlight. The almost drying water itself is portrayed in scattered diminishing trickles finding their way down the face and body; the artist continues with his intricate textural study of all hair. In this portrait, the artist further studies his own physique including the angled jaws, strong neck and wide shoulders which is consistent with features of portraiture. There is also the inclusion of a monocle or one-eyed spectacle which symbolizes the artist's balanced approach of processing decision making, especially big decisions that require careful consideration. It implies, therefore, that the portrait itself is not just about dripping water on the face but that in the moment of interaction with water, there are other overriding matters triggered or associated with that interaction. As is the case with the other portraits, the artist de-emphasizes the background in order to place focus upon the portrait itself.
The young woman stares into the distance beyond the dripping water (Plate 8) probably reflecting upon the moment of bliss. This portrait is a side study of the same individual featured in Plates 3 and 4. The reflective pose is part of the artist's style of portraying feeling beyond the representation of likeness, which is easily achieved across the three portraits featuring the same individual. The audience is left pondering upon the subject of her fascination beyond her interaction with water which though dripping down the side of her face, seems to be of peripheral importance; or perhaps she is reflective of nothing, in particular, just the peace of the moment. The execution of the portrait is very convincing with a superb study of the texture of wet African hair and smooth African feminine skin. The side view demonstrates skill in the placement of facial features as well as facial perspective. Still, the artist continues to portray his fascination with the study of crystal-clear water and how it interacts with human skin, the effect of which is refreshing and pleasant to view. This also suggests that the angle of photography is an important ingredient in the construction of a portrait since as has been seen, a face tells a story. Subsequently, how a face stares at the viewer or away from the viewer, or even the partial angles and hidden parts of it could have a bearing on the message, it may portray or may be interpreted to portray. 


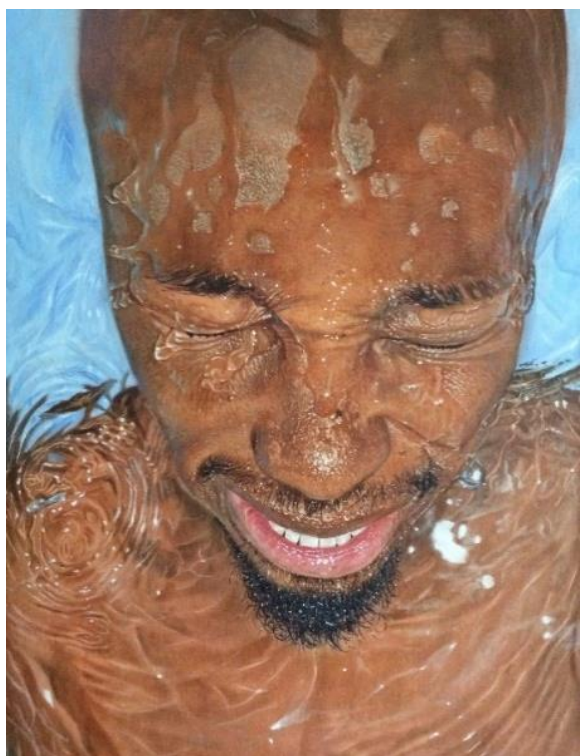

Plate 9: Self-portrait

$65 \mathrm{~cm} \times 90 \mathrm{~cm}$

Medium: Oil on canvas

2017

In another self-portrait (Plate 9) the artist starts to deviate from the study of dripping or trickling water to the distorted effect created by a bouncy or partially submerged body. When floating on crystal clear shallow waters and the body is dipped into the water, the submerged body creates waves that seem to distort the profile of the body underneath the surface of the water. The movement of the water causes swirls of waves that are almost abstract and quite interesting to observe, which is the effect the artist actually captures in this particular portrait, particularly around the shoulders. Although the face is also partially submerged, shown by the closed eyes and expression on the face, the artist still chooses to capture the intricacy of the facial details. The forehead is, however, above water as shown by the parting thin veneer of water. The artist displays great skill in his endeavour to study a rather complicated effect of a submerged body in crystal clear water. The expression on the face is another way in which the artist succeeds in depicting human feeling; you get the inclination that the subject is 'feeling' the effect of interacting

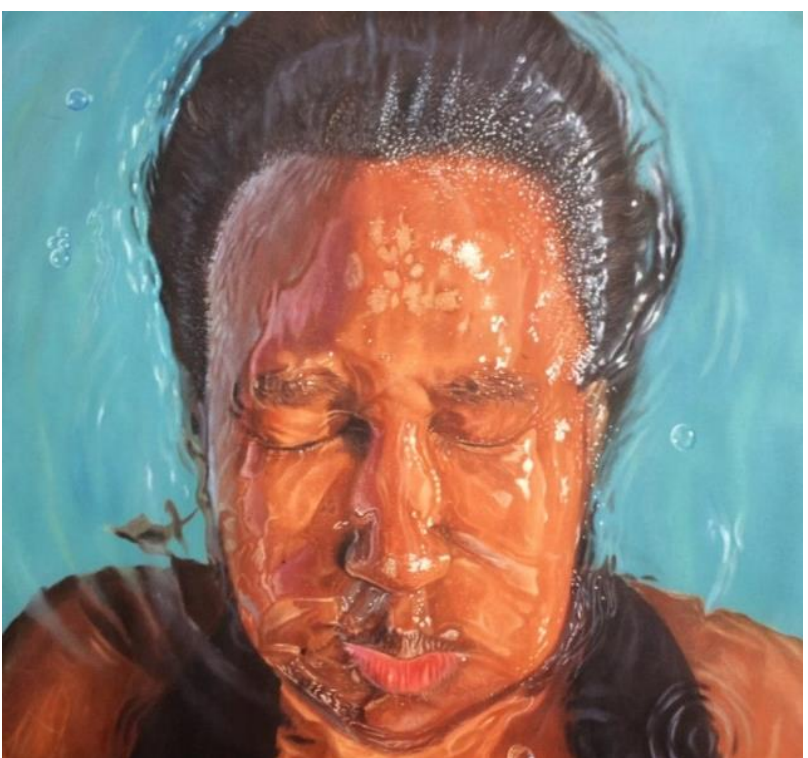

Plate 10: Crystal clear series

$85 \mathrm{~cm} \times 120 \mathrm{~cm}$

Medium: Oil on canvas

2018

with the cold water and hence expressing it through a suggestion of a slight grimace.

The woman (Plate 10) is almost entirely submerged with only a small part of her face in reprieve shown by the parting water line on her face and on the part of her hair. The artist uses interesting tonal variations to depict shadows as well as the roundness of the face including very light spots to suggest the effect of sunlight penetrating the water and shining upon the face. Despite the effect of a submerged face, the artist still studies the facial details to bring out the individual likeness in this subject. This is significant because the subject of study is the same individual featured in other portraiture (Plates 3,4\& 8); therefore, the artist not only paints the intricacy of the submerged face but also shows the facial features that underscore the consistency of likeness. Just like in Plate 9, the artist, from an interpretive perspective, brings out the feeling of the normal 'natural reaction' to what can be described as an almost sentimental and deliberate dallying with water; the closed eyes, the tightly closed lips that hold in a breath, the 
depiction of the effect of wetness and the creation of the water waves. Therefore, while the artist across all the portraits, does not purport to make any philosophical statement or commentary about the wider or complex human issues, he succeeds in portraying facial expressions that create the 'adjunct' feeling of the real human reaction to the immediate environment, in this case, the interaction with water. Beyond this, the artist goes on to suggest that these interactions do in fact result in eliciting a measure of individual joy and contentment which then can be construed to be a silent dialogue between the featured subjects and the water

\section{The Artist on his Work and Technique}

In commenting about his own work, the artist says;

'Crystal clear' is a series of works showing the study of water on the skin and talking about perception and the uniqueness of it in each individual. There's always more than meets the eye to every face; a façade with a whole world behind it, where the real stories and experiences lie. The understanding of people's real selves is the epicentre of cohesion.

Technique

My first process is choosing a subject. In most cases, I will have a subject pose for me to take photos which I would then use for my reference. I'm always keen to take high definition photographs since this has a lot to do with how detailed the painting will turn out to be I use a smooth canvas, primed with a toned primer (mostly grey or brown). My next step is sketching; I usually sketch freehand with a thin brush and thin acrylic paint. Accurate sketching really matters since this is a crucial step to an accurate representation of the subject. I then paint using oil paints, starting with the dark areas and shadows, very light layers with Burnt Umber or Burnt Sienna, then followed by the lighter colours. This helps me define volume and solidity as well as how light and darkness will fall on the subject.

The layering continues until there is a fairly smooth outcome of skin tones at which point it almost looks complete. The final stage, which consumes the most time is the addition of details. The aim here is to 'mature' as much details as possible. This is where different textures are also well defined. I use the small and soft range of needle-thin brushes for this process. The skin pores are achieved by putting dots of darker and lighter shades of the underlying skin tone together, in some instances, following a pattern and sometimes just haphazard; a process similar to neoimpressionist pointillism which needs maximum concentration and patience. I use a variety of brushes in general: soft, hard, round, pointed, flat etc. for capturing different textures and covering different areas

\section{CONCLUSION}

The main objective of a hyper-realist approach to portraiture is to use a photograph as a foundation for extracting and replicating minute details in order to depict the subject to the highest possible degree of likeness. It can be concluded that Eddie Ochieng's personal style meets the objective of his work. He confines himself here to the study of water and demonstrates a unique ability to bring out the interaction between each individual face and the water in a manner that is not only intricately executed but extracts the feeling that emanates from that interaction. One can almost 'hear' the reaction upon contact of skin and water; the gasps, the whimpering or the sighs. The profoundness of his work can therefore be seen from two perspectives; one, the excellence of execution in an otherwise tricky theme that involves the depiction of felt wetness; and two, the appeal of feeling emanating from the faces.

As has been noted, upon observing the individual portraits, one is immediately struck or fascinated by 
the execution of hyperrealism that depicts the trickling 'flow' of the almost 'liquid' crystal clear water upon the faces. The expressions on the faces themselves which would ordinarily be the focus in any other kind of portraiture, momentarily take a subsidiary role. In this regard, the water as an item of study is so powerfully rendered that it draws all attention to the onset. The effect of water upon the portraiture hence directs the visual dialogue and if indeed that was the intention of the artist, then he succeeds immensely. However, upon examining the portraits closely, once the eyes wander away from the captivating effect of the water, one cannot fail to marvel at the intricate detail of the faces themselves, the execution of which brings out the beauty of the faces as well as the feelings they exude. The fascination then continues in the way the artist is able to holistically present his portraiture using the effect of water on one hand and painting underlying facial details on the other, to depict the visual dialogue between the water and the individual persons as it would most likely be in real physical life. Across the portraiture, the artist depicts a feeling of momentary serene ecstasy as each of the individuals interacts with the water in an unspoken but very visual facial dialogue. The execution of hyperrealism in the context of the work examined in this paper has therefore been convincingly used to achieve the intended objective of the artist and is testimony to the crucial role that personal style plays in the effectiveness of artistic expression.

It can be concluded that hyperrealism, as applied in this study, is an effective style in the portrayal of feeling and emotion in portraiture through facial expression as well as the execution of minute facial details that aid this expression. In the self-portraits, the artist steps out of himself and observes himself from the outside; in the other portraits, he studies the feelings in their faces beyond the dripping water. It can also be concluded that the effectiveness of hyperrealism can be attributed to the notion that it bears minimal distraction upon the eye because it carries a photographic resemblance to the real physical face as it is recognized; hence there are no distractions of colour, textures, exaggerations, distortions or ambiguous expressions.

It can also be concluded that contemporary individual styles that tend to propagate minimalistic use of realistic representation of likeness have not diminished the effect and overall visual beauty of hyperrealism that still distinguishes it from photography, as portrayed in this series of portraiture. This clearly suggests that there is still a place for hyperrealistic portraiture and that artists in this genre should, therefore, be encouraged to pursue and apply what they perceive to be their most effective personal style to help them explore their subjects and meet their artistic and expressive goals.

\section{REFERENCES}

Barcio, P. (2016, October 3). Appreciating Abstract Portraits and Their Particular Aesthetics. Retrieved on September 6, 2020, from Ideel Art, https://www.ideelart.com/magazine/abstractportraits

Barrett, T. (1994). Principles for interpreting art. Art Education, 47(5), 8-13.

Berger Jr, H. (1994). Fictions of the pose: Facing the gaze of early modern portraiture. Representations, 46, 87-120.

Cohen, A. (2019, July 5). The Artists Putting a Contemporary Spin on Surrealism. Retrieved on September 7, 2020, from Artsy.net., https://www.artsy.net/article/artsy-editorialartists-putting-contemporary-spin-surrealism

Crozier, W. R., \& Greenhalgh, P. (1988). Selfportraits as presentations of self. Leonardo, 21(1), 29-33. 
Hertzmann, A. (2018, July 23). How Photography Became an Art Form. Can Computers Create Art? Part 1. Retrieved on September 11, 2020, from Medium, https://medium.com/@aaronhertzmann/howphotography-became-an-art-form7b74da777c63

McDonald, C. (2018, October 24). Look at me: the art of self-expression. Retrieved on September 7, 2020, from Capturemag.com.au, https://www.capturemag.com.au/advice/lookat-me-the-art-of-self-expression

Meisel, L. K. (1980) Photorealism. New York, NY: Harry N. Abrams, Inc.

Riley, C. A. (1995). Colour codes: Modern theories of color in philosophy, painting and architecture, literature, music, and psychology. London, UK: Univerity Press of New England.

Schama, S. (2015, September 4). Face value: Simon Schama on the power of portraits. Retrieved on September 12, 2020, from The Guardian, https://www.theguardian.com/books/2015/sep/ 04/simon-schama-the-face-of-britain-powerportraits

Tjintjelaar, J. (2018, September 17). On portraiture and self-portraiture in photography. Retrieved on September 13, 2020, from Bwvision.com, https://www.bwvision.com/on-portraiture-andself-portraiture-in-photography/

Wainwright L, S. (2019, December 9). Photorealism. Retrieved on September 7, 2020 from Britannica.com, https://www.britannica.com/art/Photo-realism. 